\title{
REQUISITOS DE QUALIDADE E SEGURANÇA PARA PRONTUÁRIOS DO PACIENTEi
}

\author{
REQUIREMENTS FOR QUALITY AND SAFETY RECORDS OF PATIENTS
}

Margarete Farias de Moraes ${ }^{1}$

${ }^{1}$ Doutora em Educação pela Universidade Federal do Espirito Santo (UFES).

E-mail: margamoraes@gmail.com

\section{ACESSO ABERTO}

Copyright: Esta obra está licenciada com uma Licença Creative Commons Atribuição 4.0 Internacional. $(\mathrm{(c)}) \mathrm{EY}$

Conflito de interesses: A autora declara que não há conflito de interesses.

Financiamento: Não há.

Declaração de Disponibilidade dos dados: Todos os dados relevantes estão disponíveis neste artigo.

Recebido em: 20/09/2018.

Revisado em: 01/10/2018.

Aceito em: 10/10/2018.

\section{Como citar este artigo:}

MORAES, Margarete Farias de. Requisitos de qualidade e segurança para prontuários do paciente. Informação em Pauta, Fortaleza, v. 3, número especial, p. 141-160, nov. 2018. DOI: https://doi.org/10.32810/25253468.ip.v3iEspecial.2018.39722.141-160.

\section{RESUMO}

Os serviços de saúde performam um intrincado sistema de processos, assistenciais, de apoio técnico, apoio logístico e administrativo. Estes processos requerem insumos e recursos para dar o resultado esperado, como materiais e equipamentos específicos e principalmente pessoas, além de uma adequada estrutura física. Boas práticas e métodos também são fundamentais para sustentar estes processos.
Podemos identificar a importância de vários processos de gerenciamento e controle para garantia da qualidade e segurança em saúde, como o de "Registro e tratamento de reclamações de cientes", "Registro e tratamento de falhas", "Pesquisa de satisfação", "Gestão de indicadores", "Análise crítica", "Revisão de casos", assim como "gerenciamento da qualidade e segurança das informações do paciente". Este artigo pretende apresentar e discutir os processos de gerenciamento da qualidade e segurança das informações do paciente, com base nos padrões contidos no Manual de Brasileiro de Acreditação. Foi usado como método, a análise qualitativa de um conjunto de requisitos do padrão de Gestão da Informação e Comunicação do Manual Brasileiro de Acreditação, além de apresentar conceitos sobre qualidade e segurança na saúde. O trabalho constatou a importância deste padrão para o gerenciamento de serviços e unidades de informações assistenciais.

Palavras-chave: Manual Brasileiro de Acreditação. Informação em saúde. Qualidade e segurança.

\section{ABSTRACT}

The health services perform an intricate system of processes, assistance, technical support, logistical and administrative support. These processes require inputs and resources to give the expected result, such as specific materials and equipment and especially people, in addition to an adequate physical structure. Good practices and methods are also central to sustaining these processes. We can identify the importance of various management and control processes for quality assurance and health security, such as "Registration and handling of customer complaints", "Registration and 
handling of failures", "Satisfaction survey", "Management of indicators "," Critical review ", "Case review ", as well as "quality management and patient information security". This article intends to present and discuss the processes of quality and safety management of patient information, based on the standards contained in the Manual Brasileiro de Acreditação. The qualitative analysis of a set of requirements of the Information and Communication Management standard of the Manual Brasileiro de Acreditação was used as a method, as well as presenting concepts about health quality and safety. The work noted the importance of this standard for the management of information services and units.

Keywords: Manual Brasileiro de Acreditação. Health information. Quality and safety.

\section{INTRODUÇÃO}

Os sistemas de saúde são extremamente complexos e os elementos que os compõem, como os prestadores de serviços, hospitais, clínicas especializadas, ambulatórios e laboratórios, necessitam potencializar suas gestões para dar conta das dificuldades advindas deste contexto. Esta complexidade confere ao sistema um caráter de atividade de alto risco.

As unidades de saúde performam um intrincado sistema de processos, assistenciais, de apoio técnico, apoio logístico e administrativo. Estes processos requerem insumos e recursos para dar o resultado esperado, como materiais e equipamentos específicos e principalmente pessoas, além de uma adequada estrutura física. Boas práticas e métodos também são fundamentais para sustentar estes processos.

Cada dimensão destes processos necessita ser gerenciada para permitir que os resultados sejam entregues conforme contratados, que no caso da saúde, serviços de diagnóstico e tratamento adequados às necessidades do paciente. É necessário que a unidade de saúde controle cada uma destas dimensões, alocando métodos adequados e pessoas capacitadas para este gerenciamento.

Entretanto o bom gerenciamento destas partes precisa ser complementado com outros processos que garantam o funcionamento do sistema como um todo, de forma integrada e sem falhas. Assim, é necessária a implantação de processos de gerenciamento e controle do sistema de processos, para garantir o atendimento aos requisitos institucionais de qualidade e segurança, o controle das falhas, a integração dos processos e a retroalimentação do sistema. 
Podemos identificar a importância de vários processos de gerenciamento e controle para garantia da qualidade e segurança, como o de "Registro e tratamento de reclamações de cientes", "Registro e tratamento de falhas", "Pesquisa de satisfação", “Gestão de indicadores", "Análise crítica”, "Revisão de casos", assim como "gerenciamento da qualidade e segurança das informações do paciente".

Este artigo pretende apresentar e discutir os processos de gerenciamento da qualidade e segurança das informações do paciente, com base nos padrões de contidos no Manual Brasileiro de Acreditação.

Acreditação é um procedimento voluntário, periódico e reservado de avaliação dos recursos institucionais, que tende garantir a qualidade da assistência por meio de padrões previamente aceitos. Os padrões podem ser mínimos (definindo o piso ou base) ou mais elaborados e exigentes, estabelecendo diferentes níveis de satisfação.

Podemos dizer que um estabelecimento de saúde está "acreditado" quando a disposição e organização dos seus recursos e atividades conformam um processo cujo resultado é uma assistência de saúde segura e de qualidade, a partir do cumprimento de um conjunto de padrões.

No Brasil, as instituições que estabeleceram e mantêm as determinações metodológicas do processo de acreditação são: a Organização Nacional de Acreditação ONA, que elaborou em, 1998 o Manual Brasileiro de Acreditação Hospitalar, baseado no manual da Organização Pan-Americana de Saúde (OPAS), desenvolvido, em conjunto com a Federação Latino-Americana de Hospitais em 1990; a Joint Commission, que tem representação no país, por meio de convênio com o Consórcio Brasileiro de acreditação - CBA; a Accreditation Canada International - ACI (Canadá), através de convênio firmado com o Instituto Qualisa de gestão - IQG e National Integrated Accreditation for Healthcare Organizations - NIAHO (EUA).

Para este trabalho, foram analisados os padrões referentes ao Manual Brasileiro de Acreditação, no tange aos processos de gerenciamento da qualidade e segurança das informações do paciente. A escolha se deve à longa experiencia da autora na implantação destes deste modelo em instituições de saúde públicas e privadas. 


\section{QUALIDADE E SEGURANÇA: HISTÓRICO E CONCEITOS NA SAÚDE}

As ideias de que a área de saúde precisava pensar na qualidade de seus processos e resultados é relativamente recente. 0 médico libanês Avedis Donabedian (1919-2000) foi um dos primeiros intelectuais a estruturar um pensamento de qualidade para saúde a partir da década de 1980. Donabedian concebeu um quadro conceitual muito importante para a avaliação da qualidade em saúde. Na sua concepção a qualidade de uma instituição ou serviço de saúde poderia ser avaliada pela sua estrutura, processo e resultado. Este quadro conceitual permitiu um fortalecimento do entendimento de que os serviços de saúde e suas instituições poderiam, sim, gerir e tangibilizar sua qualidade e com isso promover melhorias, para os pacientes e para elas próprias.

Como estrutura, Donabedian indicou os recursos físicos, humanos e materiais fundamentais para a assistência ao paciente. Neste sentido entende-se que estrutura mal gerida impacta negativamente nos resultados da assistência, como por exemplo a falta de estrutura adequada, a falta de profissionais qualificados e materiais vencidos ou defeituosos.

Sobre processo ele conceituou como as atividades que os profissionais executam para fins de assistência de saúde. Defendeu que quanto mais padronizada, cientificamente aceita e testada uma prática assistencial for, melhores resultados clínicos se obterá, além da prevenção de falhas.

Diante disto tudo, Donabedian concebeu a dimensão resultado como a forma de visibilizar a qualidade da assistência. Os resultados do produto final das instituições de saúde, após boas gestões da estrutura e dos processos. Para medir estes resultados, pensou em indicadores de resultado clínico, satisfação do cliente, entre outros.

0 que pode ser percebido dentro deste quadro conceitual de Donabedian é a visão de que os serviços de saúde devem ser entendidos como sistemas, e sendo assim, seus elementos, estrutura e processos, devem ser gerenciados para um objetivo comum, os resultados. Quando há um problema em um dos elementos do sistema, seja na estrutura ou no processo, não se alcança os resultados desejados. Desta forma, todos os elementos do sistema, pessoas, métodos, materiais, equipamentos e arquitetura estão diretamente interligados entre si, e do sucesso desta interconexão depende o resultado.

Donabedian, para complementar seu quadro conceitual, estabeleceu sete atributos, mensuráveis, dos resultados dos cuidados de saúde que podem definir sua qualidade. São a eficácia, efetividade, eficiência, otimização, aceitabilidade, legitimidade 
e equidade. Esses atributos puderam ajudar o entendimento do conceito de qualidade em saúde. Atributos são características que se espera de um produto ou serviço, ou ainda, o que seria próprio de se esperar de tais produtos e serviços. Abaixo o significado dos atributos da qualidade em saúde de Donabedian:

- Eficácia - Resultado final alcançado conforme o prometido ou desejado.

- Eficiência - Práticas assistenciais que ficaram dentro dos padrões estabelecidos, e que utilizam, de forma adequada, os recursos, sejam humanos ou materiais.

- Efetividade - Resultados alcançados dentro de um patamar aceitável de relação custo benefício, ou seja, foram ao mesmo tempo eficazes e eficientes.

- Otimização - Onde os recursos, sejam materiais ou humanos, foram muito bem distribuídos pela demanda, ou ainda, se utilizou menos recursos para atender mais pacientes.

- Aceitabilidade - Adaptação dos cuidados às expectativas, desejos e valores dos pacientes e seus familiares.

- Legitimidade - Possibilidade de adaptar, de forma satisfatória, um serviço aos interessados, ou à sociedade como um todo.

- Equidade - Distribuição dos serviços de acordo com as necessidades objetivas e percebidas da população. E que não haja variação em decorrência de características individuais, como gênero, etnia e condição social.

No contexto das novas reflexões sobre gestão de saúde e sua qualidade, no qual o pensamento de Donabedian teve importante contribuição, as ideias sobre aonde estavam depositados os maiores motivos para não qualidade da saúde, começaram a ser discutidas.

Um dos impulsionadores para estas reflexões vieram de um importante relatório. O Instituto de Medicina dos Estados Unidos em 1999 publicou “To Err is Human”, relatório fruto de uma pesquisa nacional nos Estados Unidos sobre mortes por tratamento de saúde. Neste relatório ficou evidente que a assistência à saúde matava mais que acidente de carro, Aids ou câncer de mama. Em 2001, outro relatório complementou o primeiro, fortalecendo ainda mais os achados sobre os erros médicos fatais nos Estados Unidos.

Os relatórios analisaram os motivos pelos quais poderiam ter levado a medicina americana, e provavelmente a do mundo que a seguia, como a do Brasil, a cometerem 
erros fatais a seus pacientes. Na análise dos relatórios, uma conjugação de fatores proporcionou o panorama de insegurança, como o rápido avanço tecnológico e científico que produziu muito conhecimento que não conseguiu se traduzir ainda eficazmente em prática assistencial. Além de ter proporcionado um aumento significativo de aparatos médicos, como medicamentos, equipamentos e materiais complexos que demandam longo tempo de treinamento para seu uso e operação de forma adequada.

Pesquisas semelhantes, usando a mesma metodologia, se espalharam pelo mundo inteiro, inclusive no Brasil. Os resultados foram bastante próximos. Os erros acometiam $10 \%$ dos pacientes assistidos e em média 50\% destes erros poderiam ter sido evitados.

Os dados impactaram o mundo inteiro e resultou em campanhas e movimentos mundiais no sentido de se diminuir o nível de erros e mortes por tratamentos de saúde inadequados. Em 2004 a OMS lança a Aliança Mundial para a Segurança do Paciente (Resolução na 57ª Assembleia Mundial da Saúde). A OMS solicitou aos países, a partir de então, mais atenção à temática da segurança do paciente.

A Aliança instruiu os países a criarem políticas públicas e ações efetivas para uma prática assistencial segura. Desde então, em toda América Latina, a segurança do paciente se tornou um importante movimento de governos, entidades, pesquisadores e profissionais de saúde.

A Segurança do paciente, para os países membros da OMS, passou a ser um compromisso que tem como base 13 diretrizes traduzidas como "Áreas de ação do Programa Segurança do Paciente da OMS”, como:

Área de ação 1 - 0 Desafio Global para a Segurança do Paciente pressupõe comprometimento e ações em segurança do paciente para minimização de risco em todos os países. Em 2005, foi lançado o primeiro Desafio Global para a Segurança do Paciente, focado na prevenção e redução das infecções relacionadas à assistência à saúde - IRAS, com o tema Uma Assistência Limpa é uma Assistência mais Segura. Em 2007, o segundo Desafio Global de Saúde do Paciente teve foco na segurança cirúrgica, com o tema Cirurgia Seguras salvam Vidas.

Área de ação 2 - Pacientes pela Segurança do Paciente asseguram que a voz do paciente esteja no centro do movimento pela saúde do paciente em todo o mundo.

Área de ação 3 - Pesquisa em Segurança do Paciente envolve pesquisas internacionais para o conhecimento da natureza do dano ao paciente e desenvolvimento de ferramentas de prevenção. 
Área de ação 4 - Taxonomia/Classificação Internacional para Segurança do Paciente desenvolve um sistema internacionalmente aceito de classificação da informação em segurança do paciente, promovendo efetivo aprendizado global.

Área de ação 5 - Relato e Aprendizagem promovem ferramentas valiosas de notificação, análise, investigação e abordagens que identificam fontes e causas de riscos, propiciando a realização de ações de aprendizado e prevenção de eventos adversos.

Área de ação 6 - Soluções para Segurança do Paciente tratam de intervenções e ações práticas para prevenção de dano ao paciente.

Área de ação 7 - Alto 5S difunde boas práticas para a mudança organizacional, clínica e de equipe, como: cuidados no preparo de soluções concentradas de eletrólitos; controle da medicação nas transições de cuidado; realização de procedimentos corretos nos sítios corretos; prevenção de falhas de comunicação durante a passagem de plantão; prevenção e redução de IRAS.

Área de ação 8 - Tecnologia para segurança do paciente foca na utilização de novas tecnologias para promoção da segurança do paciente.

Área de ação 9 - Gerenciando conhecimento irá reunir e compartilhar conhecimentos sobre a evolução mundial da segurança do paciente.

Área de ação 10 - Eliminando infecção da corrente sanguínea associada a cateter central concentrará esforços mundiais para ações de prevenção, controle e eliminação deste tipo de infecção em serviços de saúde.

Área de ação 11 - Educação para cuidado seguro desenvolve guias curriculares para estudantes da área da saúde, voltados para a segurança do paciente. Área de ação 12 Prêmio de segurança envolverá prêmios internacionais de excelência no campo da segurança do paciente, impulsionando mudança e melhoria nesta área.

Área de ação 13 - Checklists para a área da saúde vem desenvolvendo outras listas de verificação de segurança em serviços de saúde (após averiguação do sucesso da Lista de Verificação de Segurança Cirúrgica na diminuição da morbidade e mortalidade de pacientes, tais como: check-lists para Influenza A (H1N1), parto seguro e segurança do recém-nascido.

Em 2007, houve a um primeiro movimento oficial do Mercosul para efetivar os compromissos coma ONU sobre a segurança do paciente. Na XXII Reunião de Ministros da Saúde do MERCOSUL, os representantes da saúde dos respectivos países membros 
promulgaram apoio à primeira meta da Aliança Mundial para a Segurança do Paciente, o combate às infeções relacionas à assistência à saúde.

No final da década de 1990, o governo brasileiro se articulou com os diversos atores envolvidos com a saúde e lançou importantes programas para qualidade assistencial. Destaca-se o Programa dos hospitais sentinela, onde uma rede de hospitais passou a notificar eventos adversos ocorridos e compartilhar práticas seguras. Estas notificações puderam dar uma importante visão sobre os tipos de eventos recorrentes nos hospitais desta rede.

Outro destaque seria para a criação da Organização Nacional de Acreditação ONA. A ONA então passou a liderar o movimento de Acreditação no Brasil, publicando o Manual de Acreditação. 0 manual revisado periodicamente é hoje um importante guia de gestão em saúde, onde requisitos de segurança do paciente é um pilar fundamental de sua filosofia.

Apesar de muitas ações estratégicas relacionadas ao fomento da melhoria da qualidade da assistência e dos estabelecimentos de saúde terem sido observadas, nos anos que se seguiram à chama da OMS para a Aliança Mundial para a Segurança do Paciente, as políticas governamentais para segurança do paciente em âmbito nacional, se concretizaram em 2013, com a criação do Programa Nacional de Segurança do Paciente (Portaria MS/GM no 529, de $1^{\circ}$ de abril de 2013) e com a obrigatoriedade legal da implantação dos Núcleos de Segurança do Paciente (RDC n 36, de 25 de julho de 2013) nos estabelecimentos de saúde em todo o Brasil.

0 movimento mundial em prol da segurança do paciente introduziu novos atributos à qualidade da saúde. Deixando bem claro que a gestão da segurança passou a ser vista como imprescindível para qualidade e resultados do segmento saúde. Não seria mais possível organizar serviços de saúde sem considerar que os profissionais vão errar, muito menos ainda não planejar mecanismos para evitar estes erros, ou até mesmo para que eles não atinjam o paciente. Estes novos conceitos são:

Segurança - Reduzir a um mínimo aceitável, o risco de dano desnecessário associado ao cuidado de saúde.

Cuidado centrado no paciente - Respeito às necessidades, informações e valores individuais dos pacientes, onde esses valores possam orientar as decisões para o cuidado. 
Oportunidade - Possibilidade de redução do tempo de espera e atrasos, em vistas a reduzir danos aos pacientes e profissionais de saúde.

A segurança do paciente passou a ser entendida como estratégica, pois o que estava em jogo não era só as vidas perdidas, mas toda a manutenção do sistema. Os erros matam, sequelam, mas também encarecem o sistema, e isto impacta diretamente no acesso a ele. Se o sistema encarece demais, menos pessoas, instituições e governos podem pagá-lo ou mantê-lo, colocando em nível crítico de risco toda uma população, que adoece e não consegue tratamento por falta de oferta, pois sem se sustentar, o sistema vai paulatinamente encolhendo.

O movimento mundial da segurança do paciente acabou trazendo para o sistema de saúde novos conceitos, que acabaram por modificar o pensar e fazer a saúde. Estes conceitos foram expressos, e por isso acabaram sendo consenso mundial, na Classificação Internacional de Segurança do Paciente da Organização Mundial da Saúde (International Classification for Patient Safety - ICPS). As legislações brasileiras incorporaram estes conceitos. Nesta classificação encontramos conceitos fundamentais, como:

Segurança do paciente - Reduzir a um mínimo aceitável, o risco de dano desnecessário associado ao cuidado de saúde.

Dano - Comprometimento da estrutura ou função do corpo e/ou qualquer efeito dele oriundo, incluindo-se doenças, lesão, sofrimento, morte, incapacidade ou disfunção, podendo, assim, ser físico, social ou psicológico.

Risco - Probabilidade de um incidente ocorrer.

Incidente - Evento ou circunstância que poderia ter resultado, ou resultou, em dano desnecessário ao paciente.

Circunstância Notificável - Incidente com potencial dano ou lesão.

Near miss - Incidente que não atingiu o paciente.

Incidente sem lesão - Incidente que atingiu o paciente, mas não causou dano.

Evento Adverso - Incidente que resulta em dano ao paciente.

De todos os conceitos, o incidente é o que mais o profissional de saúde se depara no seu cotidiano, por isso é muito importante entendê-lo com profundidade. Veja o quadro 1 abaixo, e entenda melhor o que é incidente: 
Quadro 1 - Incidente

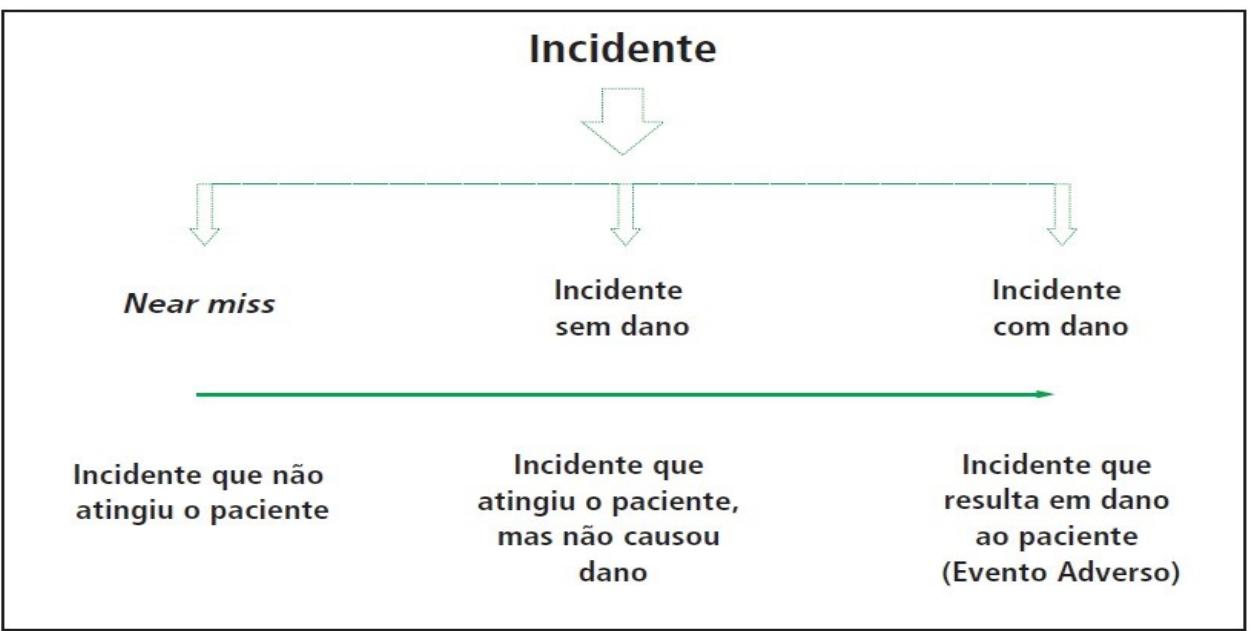

Fonte: Brasil, 2014, p. 38.

O incidente, é qualquer acontecimento, ação, evento, ou sua circustância, que poderia resultar em uma dano evitável e desnecessário ao paciente. 0 cotidiano da assistência em saúde é muito complexo, envolvendo muitos elementos, humanos e materiais. Para prestar assistência a um paciente, os profissionais utilizam conhecimento, métodos padronizados, medicamentos, formulários, materiais médicos, sistemas de compurador, equipamentos variados, entre tantos outros recursos e insumos. A operação diária da assitência, mesmo bem coordenada e planejada pode gerar riscos para o paciente. Neste ambiente complexo, muitos momentos podem se transformar em um indicidente, mesmo que não resultando danos para o paciente. Um medicamento identificado errado, um equipamento descalibrado em uso, refeições trocadas, prescrições ilegíveis, etc, etc. Uma infindável lista de situações de risco. Estas sistuações de risco concretas são incidentes, e se não trabalhadas podem provocar sérios danos à pacientes e profissionais.

Pela vasta variedade de possibilidades de incidentes foi necessário classifica-los para melhor gerenciá-los. Pois são necessárias medidas adequadas para cada tipo de incidente.

Incidentes que não chegaram a tocar o paciente, o near miss, ou quase falha, como por exemplo, a troca de nome do paciente no prontuário, percebida a tempo, erro na prescrição de medicamentos identificado antes da administração, etc. Este tipo de incidente pode não ter atingido o paciente, pois os controles planejados estão 
funcionando, mas ele não deixa de evidenciar um erro. E sabemos que, quanto mais erros nos processos, mais instáveis eles estão. Com isso mais tempo os profissionais vão perder em corrigi-lo, os retirando de seu foco, que é cuidar do paciente, além de que, na hora que o controle falhar também, o paciente é atingido.

O incidente sem dado é aquele que atingiu o paciente, mas por sorte ou alguma circunstância favorável não provocou danos ao paciente. Um medicamento administrado na dosagem errada e que não afetou a situação de saúde do paciente, uma queda sem nenhum tipo de problema, uma dieta errada servida e consumida pelo paciente sem nenhuma alteração, entre tantas outras. Estes incidentes requerem muita atenção, pois pode apontar, dependendo do volume, que os controles ou não existem ou são frágeis. É como dizer que a assistência como um todo tem um grau maior de risco, pela falta de uma gestão efetiva.

Os incidentes com dano estão em um nível de risco assistencial maior, não só os erros estão chegando aos pacientes, como eles estão provocando danos. Quanto maior o número deste tipo de incidente, mais grave está a situação de risco desta operação assistencial. É um alerta de que a gestão dos processos assistenciais e da segurança estão muito falhos ou incipientes. Estes incidentes são denominados Eventos Adversos e possuem graus de danos, a saber:

NENHUM - não houve nenhuma consequência para o paciente;

LEVE - o paciente apresentou sintomas leves, danos mínimos ou intermediários de curta duração sem intervenção ou com uma intervenção mínima;

MODERADO - o paciente necessitou de intervenção (exemplo: procedimento suplementar ou terapêutica adicional), prolongamento da internação, perda de função, danos permanentes ou em longo prazo;

GRAVE - necessária intervenção para salvar a vida, grande intervenção ou casou grandes danos permanentes ou em longo prazo;

MORTE - quando se configura morte pelo dano do Evento Adverso.

Independente da classificação do incidente, o alto volume de casos, abrangência e reincidência conotam claramente a falta de uma gestão de segurança, que garanta identificar os riscos, estabelecer procedimentos de mitigação e eliminação, treinar profissionais, controlar os casos, trata-los efetivamente e avaliar os resultados. 
A persistência e aprimoramento da gestão da segurança do paciente produz a cultura de segurança. Esta cultura proporciona um ambiente propício para prática segura, e para o tratamento adequado, e sem medo, dos incidentes que por ventura sejam identificados.

Segundo a Portaria MS/GM no 529/2013, a cultura da segurança "configura-se a partir de cinco características operacionalizadas pela gestão de segurança da organização:

1. Cultura na qual todos os trabalhadores, incluindo profissionais envolvidos no cuidado e gestores, assumem responsabilidade pela sua própria segurança, pela segu rança de seus colegas, pacientes e familiares;

2. Cultura que prioriza a segurança acima de metas financeiras e operacionais;

3. Cultura que encoraja e recompensa a identificação, a notificação e a resolução dos problemas relacionados à segurança;

4. Cultura que, a partir da ocorrência de incidentes, promove o aprendizado organizacional;

5. Cultura que proporciona recursos, estrutura e responsabilização para a manutenção efetiva da segurança"

A Segurança do Paciente é a possibilidade de redução dos atos inseguros na assistência de saúde. A possibilidade se torna uma realidade quando implanta-se uma gestão de segurança e risco, com o envolvimento de todos, que garanta práticas com resultados clinicos favoráveis ao paciente. Que ele receba tratamento adequado à sua condição de saúde, sem que este processo cause danos desnecessários.

Errar é humano. Erros na saúde são passíveis de ocorrer. Os riscos são inerentes a esta atividade e a caracteriza. 0 que devemos procurar fazer é planejar e controlar a estrutura e os processos para minimizá-los ao máximo. É possível diminuir o impacto dos erros, tanto para evitar mortes e sequelas graves, como para tornar a saúde mais efetiva, atingindo bons resultados de qualidade e produtividade, para que o sistema possa cada vez mais permitir que os cidadãos tenham acesso a ele. 


\section{MANUAL BRASILEIRO DE ACREDITAÇÃO: ORGANIZAÇÕES PRESTADORAS DE SERVIÇOS DE SAÚDE}

O Manual Brasileiro de Acreditação é a base fundamental de avaliação das instituições prestadoras de saúde, que voluntariamente, objetivam acreditar suas instituições no modelo da Organização Nacional de Acreditação - ONA.

A ONA é uma entidade não governamental, sem fins lucrativos que certifica a qualidade de serviços de saúde no Brasil. Seu foco é a segurança do paciente. Sua metodologia foi reconhecida em 2016, pela International Society for Quality in Health Care - ISQua, associação parceira da Organização Mundial da Saúde - OMS e que possui representantes de instituições acadêmicas e organizações de saúde de todo mundo.

A Acreditação Nacional pode ser obtida de forma escalonada. Pode-se pleitear o nível 1 ou Acreditado, onde é necessário atender aos critérios de segurança do paciente em todas as áreas de atividade, incluindo aspectos estruturais e assistenciais. Válido por dois anos.

Ou ainda o nível 2 ou Acreditado Pleno, onde é necessário, além de atender aos critérios de segurança, deve cumprir requisitos de gestão integrada, com processos ocorrendo de maneira fluida e plena comunicação entre as atividades. Também é válido por dois anos.

E por último o nível 3 ou Acreditado com excelência. Este nível pode ser considerado como a "excelência em gestão". É necessário atender aos níveis 1 e 2, além dos requisitos específicos de nível 3. A instituição já deve demonstrar uma cultura organizacional de melhoria contínua com maturidade institucional.

O Manual Brasileiro de Acreditação se divide em duas grandes seções, a de gestão organizacional e a de atenção ao cliente/paciente. Na primeira constam padrões para os processos que suportam toda a gestão da organização e na segunda, os processos assistenciais propriamente ditos.

Estão arrolados na seção 1, nove processos de gestão organizacional obrigatórios para todo e qualquer tipo de prestador de serviço de saúde. Além do de Gestão de Informação e Comunicação, processo chave para este trabalho, ainda constam o de Liderança, Gestão da Qualidade e Segurança, Gestão Administrativa e Financeira, Gestão de Pessoas, gestão de Suprimentos e Logística, Gestão de Acesso ao Cuidado, Gestão da Segurança Patrimonial e Gestão da Infraestrutura e da Tecnologia. 


\title{
3.1 0 Padrão de Gestão de Informação e Comunicação
}

O padrão Gestão de Informação e Comunicação tem seu escopo e conceito definido pelo manual da Organização Nacional de Acreditação (2018) como:

\begin{abstract}
Conjunto da segurança dos dados e informações, em meio físico e digital, considerando a coleta, a integração e a organização, o controle, a disponibilização, a movimentação, o recebimento, o armazenamento, a conservação e o descarte das informações. Estabelecimento de meios de comunicação interna e externa contemplando paciente/cliente e familiares, profissionais de serviços de saúde, fontes pagadoras, sociedade, órgãos de classe e terceiros e para situação de crise. (ORGANIZAÇÃO NACIONAL DE ACREDITAÇÃO, 2018, p. 45).
\end{abstract}

Podemos observar, nesta definição, padrões relacionados ao gerenciamento da informação e da comunicação institucionais, além da informação aqui tratada de forma indistinta. É um capítulo destinado ao gerenciamento geral da informação da instituição de saúde, onde também estão contidas as informações produzidas na assistência ao paciente ou para seu prontuário, mas não só.

Esta configuração é ampla ao ponto de não se definir ao certo de quem é responsabilidade deste capítulo e consequentemente, deste processo, pois o que observamos na prática é que a Gestão de Informação e Comunicação nas instituições de saúde é pulverizada em diversas instâncias clínicas e administrativas.

Este capítulo possui 19 requisitos para nível 1 e 5 para o nível 2, ou seja, 19 estruturantes do processo, ou requisitos básicos e 5 de gerenciamento, ou para seu gerenciamento. Dos 19 requisitos de nível 1, 10 são exclusivos às informações do prontuário do paciente ou acerca de informações assistenciais e 9 atingem também outras informações. Dos 5 requisitos do nível 2, 3 são exclusivos e outros 2 impactam também outras informações.

No nível 1 o capítulo de Gestão de Informação e Comunicação [...] apresenta atividades relacionadas à segurança das informações, em meio físico e digital, contemplando coleta, processamento, armazenamento e distribuição de informações. Estabelece meios de comunicação interna e externas (ORGANIZAÇÃO NACIONAL DE ACREDITAÇÃO, 2018, p. 45).

Já no nível 2, ele [...] estabelece modelo para gestão dos dados e da comunicação relevantes para o negócio, tornando-os acessíveis à liderança para tomada de decisões (ORGANIZAÇÃO NACIONAL DE ACREDITAÇÃO, 2018, p. 46). 
No quadro 2 podemos examinar os requisitos de nível 1.

Quadro 2- Requisitos do nível 1.

\begin{tabular}{|c|c|c|}
\hline Requisitos & $\begin{array}{c}\text { Relação direta e } \\
\text { exclusiva com assistência } \\
\text { ou informação do } \\
\text { prontuário }\end{array}$ & $\begin{array}{l}\text { Interpretação prática do } \\
\text { requisito }\end{array}$ \\
\hline $\begin{array}{l}\text { Dimensiona recursos } \\
\text { humanos, tecnológicos e } \\
\text { insumos de acordo com a } \\
\text { necessidade do serviço }\end{array}$ & $\begin{array}{l}\text { Não, é um requisito básico } \\
\text { para todos os processos. }\end{array}$ & $\begin{array}{l}\text { O número de pessoas, } \\
\text { equipamentos e insumos devem } \\
\text { estar de acordo com a demanda e } \\
\text { necessidades do serviço. }\end{array}$ \\
\hline $\begin{array}{l}\text { Planeja as atividades, } \\
\text { avaliando as condições } \\
\text { operacionais e de } \\
\text { infraestrutura, } \\
\text { viabilizando a execução } \\
\text { dos processos de trabalho } \\
\text { de forma segura }\end{array}$ & $\begin{array}{l}\text { Não, é um requisito básico } \\
\text { para todos os processos. }\end{array}$ & $\begin{array}{l}\text { Os serviços e processos devem } \\
\text { ser planejados previamente, } \\
\text { levando em consideração as } \\
\text { condições da operação do } \\
\text { serviço, os profissionais, os } \\
\text { equipamentos, a estrutura física } \\
\text { e os processos. }\end{array}$ \\
\hline $\begin{array}{l}\text { Define plano } \text { de } \\
\text { contingência visando ao } \\
\text { acesso e à integridade das } \\
\text { informações em sistemas } \\
\text { ou físicas }\end{array}$ & $\begin{array}{l}\text { Não, é um requisito } \\
\text { aplicável também às } \\
\text { informações } \\
\text { administrativas }\end{array}$ & $\begin{array}{l}\text { Os serviços devem planejar } \\
\text { ações para conter e atenuar } \\
\text { problemas que possam dificultar } \\
\text { o acesso e comprometer à } \\
\text { integridade das informações em } \\
\text { qualquer suporte. }\end{array}$ \\
\hline $\begin{array}{lr}\text { Organiza e integra } & \text { as } \\
\text { informações } & \text { do } \\
\text { paciente/cliente } & \\
\text { permitindo acesso ao } \\
\text { histórico a dos } \\
\text { atendimentos realizados }\end{array}$ & Sim & $\begin{array}{l}\text { O serviço deve ser capaz de } \\
\text { rastrear, e possibilitar o acesso } \\
\text { completo, a todo histórico de } \\
\text { atendimento do paciente/cliente. }\end{array}$ \\
\hline $\begin{array}{l}\text { Estabelece método para } \\
\text { registro } \\
\text { paciente/cliente, } \\
\text { permitindo a continuidade } \\
\text { do cuidado e assistência } \\
\text { adequada pela equipe } \\
\text { multiprofissional }\end{array}$ & Sim & $\begin{array}{l}\text { A estrutura de entrada e os tipos } \\
\text { de dados e informações } \\
\text { (formulários e telas) devem ser } \\
\text { planejados de forma a garantir } \\
\text { que todos os profissionais de } \\
\text { saúde, de qualquer estágio ou } \\
\text { segmento do cuidado, possam } \\
\text { acessar as informações de } \\
\text { estágios e segmentos anteriores } \\
\text { de forma a permitir uma } \\
\text { continuidade de cuidados e } \\
\text { registros. }\end{array}$ \\
\hline $\begin{array}{l}\text { Estabelece } r \text { mecanismos } \\
\text { visando à qualidade e a } \\
\text { integridade dos registros e } \\
\text { informações } \\
\text { pacientes/clientes }\end{array}$ & Sim & $\begin{array}{l}\text { Padronização de entrada de } \\
\text { dados informações (formulários } \\
\text { e telas), procedimentos de } \\
\text { autorização de registro e acesso, } \\
\text { procedimentos para o trâmite } \\
\text { dos registros analógicos, além da } \\
\text { revisão periódica dos } \\
\text { prontuários, podem garantir a } \\
\text { qualidade e integridades das }\end{array}$ \\
\hline
\end{tabular}




\begin{tabular}{|c|c|c|}
\hline Requisitos & $\begin{array}{c}\text { Relação direta e } \\
\text { exclusiva com assistência } \\
\text { ou informação do } \\
\text { prontuário }\end{array}$ & $\begin{array}{l}\text { Interpretação prática do } \\
\text { requisito }\end{array}$ \\
\hline & & $\begin{array}{ll}\text { informações } & \text { dos } \\
\text { pacientes/clientes. } & \\
\end{array}$ \\
\hline $\begin{array}{l}\text { Estabelece mecanismos e } \\
\text { procedimentos para } \\
\text { movimentação, } \\
\text { disponibilização, } \\
\text { rastreabilidade, sigilo, } \\
\text { segurança, conservação e } \\
\text { descarte da informação do } \\
\text { paciente/cliente }\end{array}$ & Sim & \begin{tabular}{lccc} 
& \multicolumn{2}{l}{ Procedimentosicos } & de \\
gerenciamento de & serviços & de \\
arquivos médicos & e ou de \\
sistemas de & prontuário \\
eletrônico. & &
\end{tabular} \\
\hline $\begin{array}{l}\text { Estabelece mecanismos e } \\
\text { procedimentos para } \\
\text { gerenciar a segurança e o } \\
\text { sigilo das informaços do } \\
\text { paciente/cliente sejam por } \\
\text { meios físicos ou virtuais }\end{array}$ & Sim & $\begin{array}{l}\text { Procedimentos para controle de } \\
\text { acesso, divulgação e uso das } \\
\text { informações de forma a } \\
\text { preservar o sigilo e a segurança } \\
\text { das informações } \\
\text { paciente/cliente. }\end{array}$ \\
\hline $\begin{array}{l}\text { Estabelece métodos para } \\
\text { coleta, organização, } \\
\text { análise e disponibilização } \\
\text { de dados estatísticos e } \\
\text { epidemiológicos, relativos } \\
\text { ao prontuário do paciente }\end{array}$ & Sim & $\begin{array}{l}\text { Definição dos indicadores e } \\
\text { métricas em geral e seus } \\
\text { métodos, produzidos a partir das } \\
\text { informações do prontuário do } \\
\text { paciente. }\end{array}$ \\
\hline $\begin{array}{lr}\text { Qualifica e } & \text { avaliação o } \\
\text { desempenho } & \text { dos } \\
\text { fornecedores } & \text { críticos, } \\
\text { alinhado à } & \text { política } \\
\text { institucionais } & \end{array}$ & $\begin{array}{lll}\text { Não, é requisito } & \text { básico } \\
\text { para muitos } & \text { outros } \\
\text { processos } & & \end{array}$ & $\begin{array}{l}\text { Estabelecer requisitos mínimos } \\
\text { para contratar fornecedores } \\
\text { importantes (aqueles que } \\
\text { impactam na entrega do } \\
\text { produto/serviço final). Após o } \\
\text { estabelecimento } 4 \text { destes } \\
\text { requisitos, qualificar os } \\
\text { fornecedores que entregarão } \\
\text { serviços e monitorar seu } \\
\text { desempenho através de visitas e } \\
\text { avaliação periódica de serviços. }\end{array}$ \\
\hline $\begin{array}{lr}\text { Estabelece diretrizes } & \text { de } \\
\text { transferência } & \text { de } \\
\text { informação entre as áreas } \\
\text { assistenciais rara } \\
\text { profissionais para } \\
\text { continuidade do cuidado }\end{array}$ & \begin{tabular}{lr}
\multicolumn{2}{l}{ Não, este requisito também } \\
pode ser aplicado à \\
passagem de $\begin{array}{l}\text { plantão, } \\
\text { comunicação }\end{array}$ verbal, \\
inclusive & ligações \\
telefônicas & \\
\end{tabular} & $\begin{array}{l}\text { Definição de quais informações } \\
\text { são críticas para a passagem do } \\
\text { paciente de um setor ou tipo de } \\
\text { atendimento para outro. }\end{array}$ \\
\hline $\begin{array}{l}\text { Estabelece e orienta os } \\
\text { usuários quanto às regras } \\
\text { de segurança da } \\
\text { informação }\end{array}$ & $\begin{array}{l}\text { Não, este requisito também } \\
\text { é aplicado para as } \\
\text { informações } \\
\text { administrativas }\end{array}$ & $\begin{array}{l}\text { Informar, por meio de vários } \\
\text { canais, quais são as regras de } \\
\text { segurança das informações da } \\
\text { instituição, para usuários dos } \\
\text { sistemas de informação }\end{array}$ \\
\hline \begin{tabular}{lr}
\multicolumn{3}{l}{ Estabelece diretrizes para } \\
o uso e acesso do \\
prontuário visando à \\
privacidade & e \\
confidencialidade & das \\
\end{tabular} & Sim & $\begin{array}{l}\text { Definição de critérios de uso e } \\
\text { acesso ao prontuário do } \\
\text { paciente. Isto inclui, consultas } \\
\text { por indivíduos internos e } \\
\text { externos, de forma a garantir sua }\end{array}$ \\
\hline
\end{tabular}




\begin{tabular}{|c|c|c|}
\hline Requisitos & $\begin{array}{c}\text { Relação direta e } \\
\text { exclusiva com assistência } \\
\text { ou informação do } \\
\text { prontuário }\end{array}$ & $\begin{array}{c}\text { Interpretação prática do } \\
\text { requisito }\end{array}$ \\
\hline informações & & confidencialidade. \\
\hline $\begin{array}{l}\text { Estabelece procedimento } \\
\text { para avaliação sistemática } \\
\text { dos registros e e } \\
\text { informações relativos à } \\
\text { assistência prestada }\end{array}$ & Sim & $\begin{array}{l}\text { Procedimento para avaliar de } \\
\text { forma contínua, a qualidade, } \\
\text { completude e lógica dos } \\
\text { registros assistenciais. Método } \\
\text { que deve ser aplicado para } \\
\text { Comissão de Revisão de } \\
\text { Prontuário }\end{array}$ \\
\hline $\begin{array}{l}\text { Organiza e disponibiliza os } \\
\text { registros clínicos de forma } \\
\text { integrada e de fácil acesso } \\
\text { á equipe de trabalho nos } \\
\text { pontos de cuidado }\end{array}$ & Sim & $\begin{array}{l}\text { Procedimentos de organização, } \\
\text { para prontuário analógico, de } \\
\text { forma que os registros estejam } \\
\text { rapidamente acessíveis e } \\
\text { prontos para uso (consulta e } \\
\text { registro). No caso de prontuário } \\
\text { eletrônico refere-se a lógica de } \\
\text { acesso às telas }\end{array}$ \\
\hline $\begin{array}{l}\text { Estabelece mecanismos } \\
\text { para organização e } \\
\text { padronização dos } \\
\text { documentos do prontuário } \\
\text { do paciente } \\
\end{array}$ & Sim & $\begin{array}{l}\text { Definição de um padrão de } \\
\text { documentos e sua lógica de } \\
\text { organização, independentemente } \\
\text { do suporte. Esta ordem deve } \\
\text { refletir a lógica do atendimento. }\end{array}$ \\
\hline $\begin{array}{lr}\text { Estabelece canais } & \text { de } \\
\text { comunicação interna } & \text { com } \\
\text { paciente/cliente } & \text { e } \\
\text { familiares } & \end{array}$ & $\begin{array}{l}\text { Não, este requisito aplica- } \\
\text { se à muitos padrões } \\
\text { assistenciais e que tenham } \\
\text { ligação com } \quad \text { o } \\
\text { paciente/cliente } \\
\text { familiares }\end{array}$ & $\begin{array}{l}\text { Estes canais podem ser } \\
\text { Ouvidoria, telefone, site, e-mail, } \\
\text { entre outros. Deve-se divulgar ao } \\
\text { paciente/cliente e seus } \\
\text { familiares quais canais e como } \\
\text { eles funcionam. }\end{array}$ \\
\hline 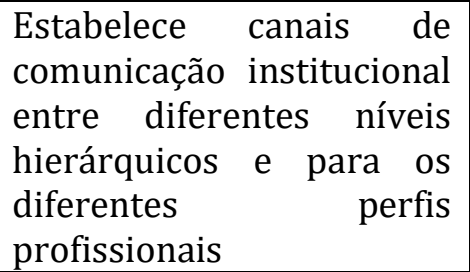 & $\begin{array}{l}\text { Não, este requisito aplica- } \\
\text { se à muitos padrões }\end{array}$ & $\begin{array}{l}\text { Estes canais podem ser e-mails, } \\
\text { reuniões específicas, murais, } \\
\text { chats, entre outros. }\end{array}$ \\
\hline
\end{tabular}

Fonte: Manual das Organizações prestadoras de Serviço, 2018.

No quadro 3 - podemos examinar os requisitos de nível 2.

Quadro 3 - Requisitos de nível 2.

\begin{tabular}{|l|l|l|}
\hline \multicolumn{1}{|c|}{ Requisito } & $\begin{array}{l}\text { Relação direta e exclusiva } \\
\text { com assistência ou } \\
\text { informação do prontuário }\end{array}$ & \multicolumn{1}{|c|}{$\begin{array}{c}\text { Interpretação prática do } \\
\text { requisito }\end{array}$} \\
\hline $\begin{array}{l}\text { Acompanha e avalia as } \\
\text { interrelações pão, é um requisito básico } \\
\text { processos, promovendo } \\
\text { ações de melhoria }\end{array}$ & $\begin{array}{l}\text { Nonitora-se se clientes e } \\
\text { para todos os processos. } \\
\text { fornecedores internos estão } \\
\text { cumprindo seus acordos. } \\
\text { Normalmente é usado registros } \\
\text { de não conformidades, queixa }\end{array}$ \\
\hline
\end{tabular}




\begin{tabular}{|c|c|c|}
\hline Requisito & $\begin{array}{l}\text { Relação direta e exclusiva } \\
\text { com assistência ou } \\
\text { informação do prontuário }\end{array}$ & $\begin{array}{c}\text { Interpretação prática do } \\
\text { requisito }\end{array}$ \\
\hline & & $\begin{array}{l}\text { dos clientes, indicadores, entre } \\
\text { outros. }\end{array}$ \\
\hline $\begin{array}{l}\text { Avalia a efetividade } \\
\text { diferentes canais } \\
\text { comunicação }\end{array}$ & $\begin{array}{l}\text { Não, é um requisito básico } \\
\text { para todos os processos. }\end{array}$ & $\begin{array}{l}\text { Avalia a efetividade dos canais } \\
\text { de comunicação estabelecidos. } \\
\text { Normalmente é usado registros } \\
\text { de não conformidades, queixa } \\
\text { dos clientes, indicadores, entre } \\
\text { outros. }\end{array}$ \\
\hline $\begin{array}{l}\text { Utiliza os resultados da } \\
\text { análise de prontuário para } \\
\text { promover ações de } \\
\text { melhoria }\end{array}$ & Sim & $\begin{array}{l}\text { Analisa os resultados das } \\
\text { avaliações de prontuário e cria } \\
\text { plano de ação de melhoria no } \\
\text { que tange aos aspectos } \\
\text { avaliados. Monitoramento com } \\
\text { indicadores das melhorias } \\
\text { implementadas. }\end{array}$ \\
\hline $\begin{array}{lrr}\text { Estabelece } & \text { plano } & \text { de } \\
\text { treinamento } & & \text { para } \\
\text { modificações } & \text { e } \\
\text { incorporações } & \text { de } & \text { novos } \\
\text { documentos do prontuário }\end{array}$ & Sim & $\begin{array}{l}\text { Modificação de entrada de } \\
\text { dados e informações no } \\
\text { prontuário (formulários e telas), } \\
\text { bem como falhas detectadas, } \\
\text { devem ser informadas e } \\
\text { garantidos treinamentos para os } \\
\text { profissionais envolvidos. }\end{array}$ \\
\hline $\begin{array}{l}\text { Estabelece diretrizes para } \\
\text { coleta de dados do } \\
\text { prontuário, preservando a } \\
\text { confidencialidade dos } \\
\text { profissionais e pacientes } \\
\text { envolvidos }\end{array}$ & Sim & $\begin{array}{l}\text { Definição de critérios de } \\
\text { coletada de dados e informações } \\
\text { do prontuário r do } \\
\text { paciente/cliente. os critérios } \\
\text { incluem quem pode coletar e em } \\
\text { quais circunstâncias } \\
\text { finalidades. }\end{array}$ \\
\hline
\end{tabular}

Fonte: Manual das Organizações prestadoras de Serviço, 2018.

\section{CONCLUSÃO}

Os requisitos de nível 1 apontam para a necessidade de planejamento e execução de um processo de gestão de informação e comunicação que esteja dimensionado e estruturado adequadamente para as demandas e tamanho do serviço. Este nível aponta para a necessidade premente de gerenciamento da segurança das informações quando requer que se tenha critérios para acesso e uso dos dados e informação, padrão para entrada de dados, mecanismos de avaliação das informações, procedimentos de tratamento e manuseio dos dados e informações, além da exigência da educação, tanto para equipes internas e pacientes, quanto da necessidade de se cumprir as normas de segurança das informações. 
Neste nível também se estabelece que é necessário definir procedimentos para a ordenação, rastreabilidade, análise, processamento, registro, armazenamento e movimentação de informações e documentos gerados pela assistência ao paciente. Também neste nível é necessário estabelecer formas de qualificar e avaliar fornecedores críticos envolvidos com a questão informacional da organização.

No nível 2, constata-se requisitos ligados ao gerenciamento e garantia da efetividade do processo de Gestão de Informação e Comunicação, como a exigência de avaliação da interação deste processo com outros, o uso das avaliações dos prontuários para gerar melhoria em toda a cadeia de cuidado e no próprio registro. Neste nível podemos constatar a necessidade de treinar os profissionais, a partir das mudanças geradas pelas mudanças na estrutura de entrada de dados e informações, sejam estas mudanças motivadas para melhorar o fluxo de atendimento, seja para corrigir problemas de registro, integridade, segurança e acesso às informações do paciente/cliente.

Com este trabalho foi possível evidenciar que o padrão de Gestão de Informação e Comunicação do Manual Brasileiro de Acreditação para Organizações Prestadoras de Serviços de Saúde aborda de forma abrangente e profunda a questão da qualidade e segurança das informações e documentos gerados pela assistência ao paciente/cliente. Com isso podemos considerá-lo um guia importante nesta gestão.

O conjunto de requisitos deste padrão pode ser usado, tanto em discussões teóricas como em questões práticas de gerenciamento de serviços ou unidades de informação em saúde, pois ele abrange e orienta os processos de gerenciamento, análise, registro e uso das informações e dados em saúde, principalmente no que tange às informações da assistência ao paciente.

\section{REFERÊNCIAS}

BRASIL. Agência Nacional de Vigilância Sanitária, Gerência de Vigilância e Monitoramento em Serviços de Saúde, Gerência Geral de Tecnologia em Serviços de Saúde. Assistência Segura: Uma Reflexão Teórica Aplicada à Prática. Brasília: Anvisa, 2013.
BRASIL. Agência Nacional de Vigilância Sanitária. Implantação do Núcleo de Segurança do Paciente e Serviços de Saúde. Brasília: Anvisa, 2014.

BRASIL. Agência Nacional de Vigilância Sanitária. Implantação do Núcleo de 
Segurança do Paciente e Serviços de Saúde. Brasília: Anvisa, 2011.

BRASIL. Ministério da Saúde. Documento de referência para o Programa Nacional de Segurança do Paciente. Brasília: Ministério da Saúde, 2014.

BRASIL. Portaria no 529, de 1 de abril de 2013. Institui o Programa Nacional de Segurança do Paciente (PNSP). Brasília, Ministério da Saúde. Disponível em: $<$ https://bit.ly/2P2iiht $>$. Acesso em: 10 jun. 2018.
DONABEDIAN, A. The seven pillars of quality. Arch Pathol Lab Med, v. 114, n. 11, 1990.

ORGANIZAÇÃO NACIONAL DE ACREDITAÇÃO. Manual de Acreditação das Organizações prestadoras de Serviço. Brasília: Anvisa, 2018.

PATIENT safety is not a luxury. The Lancet, [S.l.], v. 387, n. 10024, 2016, p. 1133.

Disponível em: <https://bit.ly/2QgZAHD>. Acesso em: 10 jun. 2018. DOI: http://doi.org/cxcr.

\section{NOTAS}

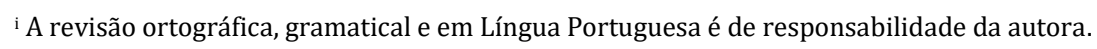

